American Journal of Economics and Business Administration 3 (2): 401-404, 2011

ISSN 1945-5488

(C) 2011 Science Publications

\title{
Small Business Entrepreneurs: A Focus on Fraud Risk and Prevention
}

\author{
Doug Laufer \\ Metropolitan State College of Denver, Campus Box 80, P.O. Box 173362, \\ Denver, CO 80217-3362, USA
}

\begin{abstract}
Problem statement: Small businesses have unique problems in fighting fraud. Typically there are limited resources devoted to anti-fraud efforts by small businesses. Employee fraud typically results in monetary loss, often not recovered, investigation expenses and negative impact on employee productivity and morale. Conclusion/Recommendations: This study provides information to assist the small business entrepreneur in identifying potential fraud risks and to enhance their organization's fraud prevention measures.
\end{abstract}

Key words: Fraud examiners, fraud risk, fraud prevention, small business entrepreneurs

\section{INTRODUCTION}

Fraud is rampant today and imposes enormous costs on business organizations globally. According to the Association of Certified Fraud Examiners (ACFE) 2010 Report to the Nation, typical organizations lose $5 \%$ of annual revenue to fraud. That translates to losses of \$2.9 trillion based on 2009 Gross World Product (Association of Certified Fraud Examiners, 2006). In light of current global economic conditions it is likely that fraud is on the increase. According to a recent online poll conducted by Deloitte nearly two-thirds (63.3\%) of executives polled expect fraud to increase during the next two years (Deloitte Financial Advisory Services LL, 2009).

Small businesses have unique problems in fighting fraud and accordingly bear a greater burden and are at a greater risk of fraud than their larger corporate counterparts. Larger organizations devote more resources to preventing fraud. Typically there are limited resources devoted to anti-fraud efforts by small businesses. On the average small businesses, compared to larger organizations, lack hot lines and anonymous reporting systems, do not have internal audit departments, have weaker internal control systems and do not conduct fraud training for their employees. Additionally, chances are, small business owners become victims because they don't think they are at risk. "I trust my employees", many business owners think. "We're so small, we're all friends", they say. "No one here would steal from me" (Tootle, Nick, 2010).

Small businesses suffer a much higher rate of fraud than larger organizations. Organizations with fewer than 100 employees experienced more fraud occurrences than larger businesses. The median loss suffered per fraud occurrence by these small businesses was $\$ 200,000$, which is $37 \%$ higher than average median loss for larger organizations (Association of Certified Fraud Examiners, 2008a; 2008b). These losses can be crippling to a small business.

Purpose: The purpose of this study is to provide information to assist the small business entrepreneur to identify potential fraud risks and to enhance their organization's fraud prevention measures.

Fraud risks: To understand possible fraud risks it is also helpful to know the three characteristics that enable any fraud. Often referred to as the fraud triangle, the components are: perceived pressure, rationalization and perceived opportunity (Fig. 1).

Employees who steal and commit fraud against a small business must have motivation or perceived pressure to do so. Possible sources of pressures include:

- Unexpected financial pressures

- Living beyond one's means

- Pressures created by vices such as gambling or drug use

- Poor credit or money management skills

- Greed

Company culture and tone at the top are extremely important attributes in minimizing rationalization. Most employees who commit fraud have no criminal history; accordingly, they must somehow rationalize their actions to themselves. Rationalization is an attribute distinctive within each individual. Typical rationalizations include:

- I am only "borrowing" the money

- I deserve it

- The company does not appreciate me
- It really does not hurt anyone 


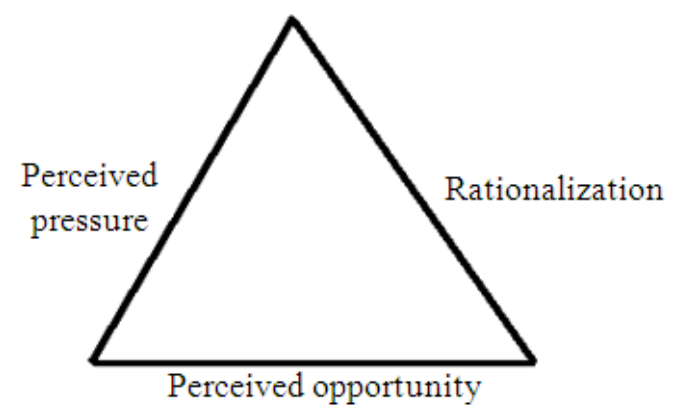

Fig. 1: Fraud triangle

Table 1: The sum of percentages in this table exceeds $100 \%$ because several cases involved schemes from multiple categories

Methods of fraud in small businesses ( $<100$ Employees)-537 Cases

\begin{tabular}{lll} 
Scheme & Number of cases & Percent of cases \\
\hline Billing & 154 & $28.70 \%$ \\
Check Tampering & 140 & $26.10 \%$ \\
Corruption & 137 & $25.50 \%$ \\
Skimming & 116 & $21.60 \%$ \\
Expense Reimbursements & 90 & $16.80 \%$ \\
Non-Cash & 80 & $14.90 \%$ \\
Cash on Hand & 79 & $14.70 \%$ \\
Payroll & 72 & $13.40 \%$ \\
Larceny & 66 & $12.30 \%$ \\
Financial Statement Fraud & 30 & $5.60 \%$
\end{tabular}

Source: ACFE 2010 Report to the Nation

Even if an employee has perceived pressures and can rationalize his/her actions; the fraud perpetrator must also perceive an opportunity to commit fraud and then conceal it, or at least avoid being punished. If someone does not have the opportunity to commit fraud, even if perceived pressures and rationalizations are present, the fraud risk is minimal.

The amount of opportunity an employee has to commit fraud is usually a function of their position of authority and level of trust. Poor internal controls can significantly increase the opportunity for fraud. Organizational structure, lack of security measures (internal audit, surveillance) hiring practices, discipline of perpetrators, ignorance, apathy and incapacity can all be factors in opportunity to commit fraud.

Considering the potential fraud exposure it behooves the small business entrepreneur to know what types of fraud are most typical in small businesses. According to the ACFE 2010 Report to the Nation $86.3 \%$ of all frauds perpetrated against companies are asset misappropriations (NFIB, 2010).

Misappropriation of assets can be further broken down between cash and non-cash misappropriations. Cash is the most commonly stolen asset. Misappropriation of cash includes skimming (taking cash before it's recorded), cash larceny (taking cash after it's recorded, but before it's deposited), or fraudulent disbursements. Schemes involving the disbursement of cash include frauds related to billing, expense reimbursement, check tampering, payroll, wire transfers and register disbursements. Table 1 summarizes the fraud schemes in 537 reported small business fraud cases.

Note that three of the top four methods of fraud in small businesses are billing schemes, check tampering and skimming. These schemes, as well as payroll fraud, are significantly more common in small businesses than in their larger counterparts. Much small business fraud involves situations where controls are weak and duties are not segregated. Small business entrepreneurs should be continually assessing fraud risks in their organization and identifying weaknesses. Steps should be taken to deter employee fraud; fraud prevention measures will be addressed.

Fraud prevention: Simply stated fraud prevention is cheaper than fraud detection. On the average the typical fraud scheme takes 18 months or more to detect. Once a fraud is discovered the victim organization may incur additional losses in terms of legal expenses, bad publicity, lower productivity and morale and other consequences. Often the stolen or embezzled funds are not recovered. Accordingly, small businesses should take proactive steps to prevent fraud. Important features that help prevent fraud in the workplace are discussed below.

Preventing employee fraud should start before the employee is hired. Hire honest individuals and provide them fraud awareness training. Conduct background checks. Check past employment and references and verify education and certifications. Check for criminal convictions.

Internal controls refer to an organization's system of checks and balances designed to ensure reliable financial reporting, effective and efficient operations, safeguarding assets against theft and unauthorized use and compliance with applicable laws and regulations. The Committee of Sponsoring Organizations of the Treadway Commission (2009a; 2009b) provides guidance to help small businesses evaluate their internal control system.

Having a good internal control system in place is paramount in minimizing the opportunity for fraud. It is especially important to have a system that provides for segregation of duties. Segregation of duties is the cornerstone of a good internal control system. Internal control systems should have checks and balances to ensure two or more employees handle separate parts of 
Am. J. of Economics and Business Administration 3 (2): 401-404, 2011

a transaction. Other features of an internal control system include:

- Requiring proper authorization of expenses, time sheets and the like

- Separate custody of the asset from the recordkeeping responsibility

- Ensuring that there is adequate documentation to support transactions, accounting reports and statements.

- Reconciliation of bank accounts every month. The reconciliation should be completed by a person who doesn't have check signing or general ledger responsibilities

- Monitoring cash activity. Consider use of security cameras. People perceive less opportunity to commit fraud if they think they are being watched.

- Conducting surprise cash counts and audits

- Protecting checks against fraudulent use by prohibiting writing checks payable to cash, limiting access to the checks and storing checks under lock and key

- Ensuring that all cash and checks received are promptly recorded and deposited

- $\quad$ Restricting the use of credit cards and verifying all charges made to credit cards were business-related. Require employees to submit itemized, original receipts for all purchases

- Requiring mandatory vacations. It is a red flag if an employee does not take vacations. Fraudsters are afraid to go on vacation because they fear someone will uncover their scheme

Table 2 provides information on how frauds were first discovered in small businesses. The most common method for catching fraud in a small business was through tips. Accordingly, employees should be provided with methods to anonymously report suspected fraud activity. Many employees are hesitant to report suspicious activity; therefore the small business entrepreneur should consider utilizing a third party hotline service.

It is important to have a clear policy for dealing with dishonestly and it is critical the policy is followed. There should be expectation of punishment and it should be publicized. Merely firing an employee who committed fraud in not an adequate response; it passes the problem on to future employers and it sends the wrong message to the other employees. The incident of fraud should be investigated thoroughly and disciplinary action should be taken against the perpetrator, possibly including civil or criminal prosecution.
Table 2: Initial detection of frauds in small businesses $(<100$ Employees)-537 cases

\begin{tabular}{ll}
\hline Detection method & Percent of cases \\
\hline Tip & $33.30 \%$ \\
Management review & $15.30 \%$ \\
By accident & $12.10 \%$ \\
Account reconciliation & $9.20 \%$ \\
Internal audit & $8.20 \%$ \\
Document examination & $7.90 \%$ \\
External audit & $7.10 \%$ \\
Notified by police & $2.90 \%$ \\
Surveillance & $2.10 \%$ \\
Confessions & $1.70 \%$ \\
IT Controls & $0.20 \%$ \\
\hline
\end{tabular}

Source: NFIB (2010) Report to the Nation

Small business entrepreneurs must also be aware of external fraud threats. The ACFE provides guidance to small businesses in coping with fraud related issues in their Small Business Fraud Prevention Manual (Association of Certified Fraud Examiners, 2004). The most common external fraud schemes are perpetrated by vendors. There are a number of web sites that can help small business entrepreneurs distinguish between legitimate vendors and illegitimate businesses, these include:

- $\quad$ Federal trade commission: The FTC website lists a company's current licensing status

- Better business bureau: Their website allows searches to find any complaints filed against a company

- National consumers league: Information about telemarketing and internet scams are detailed at the National Fraud Information Center and Internet Fraud Watch www.fraud.org

- Secretary of State or Attorney General's Officemost states provide websites that allow you to research specific information about a company, including articles of incorporation, officers and certificate of good standing

A 2009 research study showed that organizations with strong ethical values from top executives to middle managers to workers experience less misconduct, more frequent reporting of misbehavior and less retaliation on the job (Ethics Resource Center, 2009a; 2009b). Accordingly, the most effective thing an entrepreneur can do personally to prevent fraud is to lead by example. Set the tone of your workplace. The ethical environment set by the small business owner in the workplace, by words and deeds, is the model employees will follow. The tone-at-the-top should model behavior that is in compliance with organizational policies and procedures. Reinforce through personal action that unethical behavior will not be tolerated. 
Am. J. of Economics and Business Administration 3 (2): 401-404, 2011

\section{CONCLUSION}

Regardless of how and why fraud is perpetrated the result is the same for the small business entrepreneur; monetary loss that is often not recovered, costs incurred to investigate and resolve the fraud and negative impact on employee productivity and morale. To avoid being a fraud victim small business entrepreneurs should identify fraud risks within their organization and, arm themselves with this increased awareness of risk, improve anti-fraud measures in an effort to help prevent losses from fraudulent activities.

\section{REFERENCES}

Association of Certified Fraud Examiners, 2004. Small Business Fraud Prevention Manual. Austin, TX.

Association of Certified Fraud Examiners, 2006. The Small Business Fraud Prevention Manual. Association of Certified Fraud Examiners, Austin, TX., ISBN 1889277355, pp: 234,

Association of Certified Fraud Examiners, 2008a. 2008

Report to the Nation on Occupational Fraud and Abuse. Austin, TX, pp: 26.

Association of Certified Fraud Examiners, 2008b. Report to the Nation on Occupational Fraud and Abuse. 1st Edn., Association of Certified Fraud Examiners, Austin, TX., pp: 67.
Committee of Sponsoring Organizations of the Treadway Commission, 2009a. Guidance on Monitoring Internal Control Systems. www.coso.org

Committee of Sponsoring Organizations of the Treadway Commission, 2009b. Guidance on Monitoring Internal Control Systems. American Institute of Certified Public Accountants, New York, ISBN: 0870517953, pp: 28.

Ethics Resource Center, 2009a. The Importance of Ethical Culture: Increasing Trust and Driving Down Risks. National Business Ethics Survey. http://www.ethics.org/news/strong-ethical-culturekey-cutting-misconduct-job

Ethics Resource Center, 2009b. The Importance of Ethical Culture: Increasing Trust and Driving Down Risks. Ethics Resource Center. http://www.ethics.org/resource/importance-ethicalculture-increasing-trust-and-driving-down-risks

NFIB, 2010. Fraud and the Small Business. National Federation of Independent Business. http://www.nfib.com/business-resources/businessresources-item/cmsid/45608/

Tootle, Nick, 2010. Fraud and the Small Business. National Federation of Independent Business. http://www.nfib.com/business-resources/businessresources-item/cmsid/45608/ 